\title{
Analysis of polyphenolic metabolites from Artemisia gmelinii Weber ex Stechm. and regional comparison in Korea
}

\author{
Mi Hyeon Park ${ }^{1}$ - Doo-Young Kim ${ }^{1}$ Hyun-Jae Jang ${ }^{1}$ Yang Hee Jo ${ }^{1}$ Jin Tae Jeong ${ }^{2}$. \\ Dae Young Lee ${ }^{2}$ Nam-In Baek ${ }^{3}$ Hyung Won Ryu ${ }^{1}$ (D) Sei-Ryang $\mathrm{Oh}^{1}$ (D)
}

Received: 6 November 2019 / Accepted: 20 November 2019 / Published Online: 31 December 2019

(C) The Korean Society for Applied Biological Chemistry 2019

\begin{abstract}
Artemisia species are widely used as food ingredients and raw material in traditional medicine. However, to date, the secondary metabolites of Artemisia gmelinii Weber ex Stechm. have not been sufficiently investigated. The secondary metabolites of A. gmelinii, which was collected from representative regions in Chungbuk, Gangwon, and Gyeongbuk, were analyzed using ultraperformance liquid chromatography-quadrupole time-of-flight mass spectrometry (UPLC-QTof MS) combined with an unsupervised principal component analysis (PCA) multivariate analysis. In the loading scatter plot of PCA, significant changes in metabolites were observed between the regions, ten metabolites (3: 5-Ocaffeoylquinic acid, 4: 4-O-caffeoylquinic acid, 8: transmelilotoside, 12: quercetin 3- $O$-hexoside, 15: 3,4- $O$-dicaffeoylquinic acid, 17: 3,5-O-dicaffeoylquinic acid, 18: 4,5-O-dicaffeoylquinic acid, 19: syringaldehyde, 20: caffeoylquinic acid derivative, and 23: icariside II) were evaluated as key markers among twenty-five identified metabolites. Interestingly, the contents of the identified marker significantly differed between the three groups. This is the first study to report the presence of marker metabolites and their
\end{abstract}

Hyung Won Ryu $(\bowtie)$

E-mail: ryuhw@kribb.re.kr

Sei-Ryang $\mathrm{Oh}(\triangle)$

E-mail: seiryang@kribb.re.kr

${ }^{1}$ Natural Medicine Research Center, KRIBB, 30-Yeongudanji-ro, Ochangeup, Cheongwon-gu, Cheongju-si, Chungbuk 28116, Republic of Korea

${ }^{2}$ Department of Medicinal Crop Research, National Institute of Horticultural and Herbal Science, RDA, Eumseong 27709, Republic of Korea

${ }^{3}$ Graduate School of Biotechnology, Kyung Hee University, Yongin 17104, Republic of Korea

This is an Open Access article distributed under the terms of the Creative Commons Attribution Non-Commercial License (http://creativecommons. org/licenses/by-nc/3.0/) which permits unrestricted non-commercial use, distribution, and reproduction in any medium, provided the original work is properly cited. correlating geographical cultivation in A. gmelinii.

Keywords Artemisia gmelinii · Caffeoylquinic acid · Metabolites - Region · Ultra-performance liquid chromatography-quadrupole time-of-flight mass spectrometry

\section{Introduction}

Artemisia (Asteraceae) is the largest and widespread genus that is used in folk medicine all over the world [1]. Artemisia contain large amounts of polyphenols that have been reported to have glucose-lowering [2], antidiabetic [3], antimicrobial [4], antitumor [5], antimalarial [6], and antioxidant activity [7] for the prevention and therapeutic treatment of various diseases. There have been many studies on other species from Artemisia genus, but Artemisia gmelinii Weber ex Stechm. has been studied only for its polyphenolic content (e.g., flavone glycoside, coumarin, and phenolic acid derivatives) with antioxidant activity in the aerial parts of methanolic extract [7]; however, to date, the regional variation in its polyphenolic content has not been studied. Because the physiological changes in polyphenolic content are affected by environmental conditions, the content difference by region is thought to be important for the quality control of $A$. gmelinii [8].

Currently, metabolomics tools (i.e., statistical and multivariate data) are essential for studying various aspects of natural products and plant metabolites including dereplication, biological activity screening, chemotaxonomy, and quality control [9-14]. Ultraperformance liquid chromatography-quadrupole time-of-flight mass spectrometry (UPLC-QTof MS)-based metabolomics is useful for the rapid and highly sensitive detection of secondary metabolites from plant biosynthesis pathways $[11,14]$. Interestingly, technologies that use high-resolution mass spectrometry (HRMS) have improved detection and quantification strategies of assessing structural information to reveal diverse metabolites. In addition, 
various plants (e.g., Agastache rugose, Spinacia oleracea, Sophora flavescens, Panax ginseng, Euphorbia supine, and Hordeum vulgare) have been investigated using UPLC-QTof MS [9-14]. Specifically, the physiological changes of many flavonoids was depend on the cultivation conditions using temperatures, light, drought, salt, biotic stresses, genetics, and agronomic conditions $[8,10]$. Therefore, for quality assurance and raw material standardization of geographical spinach, it is also important to develop flavonoid markers which can be used as the reference materials. In addition, the effect of cultivation regions on metabolomics profiles of $A$. gmelinii has not been evaluated yet. Furthermore, metabolomic studies provide a new approach for monitoring change in metabolite quality of plant cultivation regions in Korea. Therefore, in this study, the metabolomic analysis of polyphenolic content in A. gmelinii was carried out to discriminate cultivation regions in Korea; the analysis identified key markers based on polyphenolic contents using UPLC-QTof MS coupled with multivariate analysis.

\section{Materials and Methods}

\section{Plant materials and reagents}

Two samples [Chungbuk (CB) and Gyeongbuk (GB)] of Artemisia gmelinii were collected at province farms, and other samples [Gangwon $(\mathrm{GW})$ ] were collected at the farms from Seorim-ri, Seo-myeon, Yangyang-gun, Gangwon-do in South Korea in September 2019. The plants were authenticated by Dr. Jin Tae Jeong [National Institute of Horticultural and Herbal Science, Rural Development Administration (RDA)], and a voucher specimen (MPS006276, MPS006277) was deposited at the Department of Medicinal Crop Research, RDA, Eumseong, Republic of Korea. Detailed information on the collected samples, including the number of samples, and cultivation regions is displayed in Supplementary Table 1. The organic solvents for extraction and chromatographic analysis were purchased from Merck (Darmstadt, Germany). Ultra-pure water was prepared using a purification system (Milli-Q Academic, Merck Millipore).

\section{Sample preparation}

The powdered samples (5 samples from each region) of dried $A$. gmelinii aerial part $(100.0 \pm 0.5 \mathrm{mg})$ were prepared and extracted in $60 \%$ prerthanol A with sonication (SD-350H, sd-ultra, Seoul, Korea) for $15 \mathrm{~min} \times 3$ times. After filtration, the extract was concentrated in vacuo and dissolved in methanol for analysis.

\section{UPLC-QTof MS conditions for the secondary metabolites analysis}

Flavonoid profiling analyses were performed on a Waters ACQUITY UPLC ${ }^{\mathrm{TM}}$ System (Waters, Milford, CT, USA) coupled to a Micromass QTof Premier ${ }^{\mathrm{TM}}$ mass spectrometer (Waters). For profiling analyses, the gradient conditions of mobile phases were 0.0-1.0 min 5\% B; 1.0-20.0 min 5-100\% B; 20.0-22.3 min $100 \%$ B; $22.3-22.4$ min $100-5 \%$ B; 22.4-25.0 min 5\% B [(A) water with $0.1 \%$ formic acid, (B) acetonitrile with $0.1 \%$ formic acid] at 0.4 $\mathrm{mL} / \mathrm{min}$ with a BEH C18 column $(2.1 \times 100 \mathrm{~mm}, 1.7 \mathrm{~mm}$, Waters $)$. The QTof MS was analyzed using the following conditions: source desolvation temperature $\left(110\right.$ and $\left.350{ }^{\circ} \mathrm{C}\right)$, capillary and cone voltage ( $2.3 \mathrm{kV}$ and $50 \mathrm{~V}$, respectively) in a negative mode. Leucine-enkephalin (reference lock mass of $[\mathrm{M}-\mathrm{H}]^{-} \mathrm{m} / \mathrm{z} 554.2615$ ) was used as the reference solution at a flow rate of $2 \mathrm{~mL} / \mathrm{min}$. Accurate mass, $\mathrm{MS}^{2}$ and elemental compositions were calculated using the MassLynx software (Waters) to analyze the tentative metabolites of the identified peaks.

\section{Data processing and multivariate data analysis}

For the comparative analysis of flavonoids from A. gmelinii aerial parts, the data were processed using UPLC-QTof MS with the MarkLynx software (Waters) to obtain a three-dimensional matrix of markers (e.g., accurate masses, retention times, and intensities). Then, the resulting data set was exported to the SIMCA $\mathrm{P}^{+}$ software 12.0 (Umetrics, Umeå, Sweden) for multivariate statistical analysis.

Table 1 Information of environmental conditions by Korea Meteorological Administration (http://www.kma.go.kr/)

\begin{tabular}{|c|c|c|c|c|c|c|c|}
\hline 2019 year & Province & Apr. & May. & Jun. & Jul. & Aug. & Sep. \\
\hline \multirow{3}{*}{$\begin{array}{l}\text { temperature }{ }^{\circ} \mathrm{C} \\
(\min / \max )\end{array}$} & GW & $6.9 / 16.6$ & $14.7 / 25.0$ & $16.6 / 24.1$ & $21.8 / 28.0$ & $22.7 / 29.4$ & $17.5 / 24.7$ \\
\hline & $\mathrm{CB}$ & $2.4 / 17.6$ & $8.5 / 26.1$ & $14.9 / 27.6$ & $19.7 / 29.1$ & $20.4 / 31.2$ & $15.2 / 26.1$ \\
\hline & GB & $5.9 / 19.6$ & $11.3 / 27.7$ & $16.3 / 28.2$ & $21.4 / 30.0$ & $22.5 / 32.1$ & $17.9 / 27.2$ \\
\hline \multirow{3}{*}{$\begin{array}{l}\text { monthly precipitation } \\
\quad(\text { snowfall, } \mathrm{mm})\end{array}$} & GW & 80.9 & 5.7 & 97.8 & 234.4 & 293.5 & 209.9 \\
\hline & $\mathrm{CB}$ & 58.1 & 26.1 & 90.0 & 158.6 & 99.1 & 164.5 \\
\hline & GB & 79.5 & 23.0 & 242.1 & 105.7 & 174.4 & 157.0 \\
\hline \multirow{3}{*}{$\begin{array}{l}\text { relative humidity } \\
\qquad(\%)\end{array}$} & GW & 55.0 & 52.3 & 78.2 & 79.6 & 77.9 & 79.1 \\
\hline & $\mathrm{CB}$ & 56.1 & 51.4 & 66.2 & 75.1 & 75.3 & 77.3 \\
\hline & GB & 52.9 & 49.1 & 66.0 & 73.1 & 72.7 & 77.4 \\
\hline \multirow{3}{*}{$\begin{array}{l}\text { sunshine duration } \\
\text { (hr) }\end{array}$} & GW & 230.5 & 296.2 & 224.8 & 196.0 & 230.7 & 145.2 \\
\hline & $\mathrm{CB}$ & 186.4 & 284.2 & 208.2 & 129.3 & 183.6 & 113.5 \\
\hline & GB & 200.2 & 298.3 & 238.9 & 162.3 & 216.4 & 138.3 \\
\hline
\end{tabular}


(A)

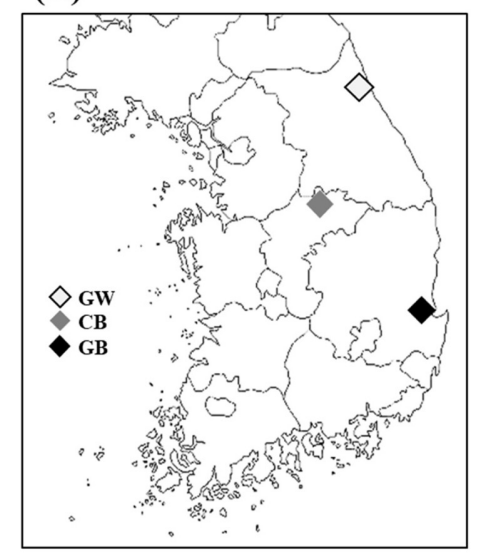

(B)

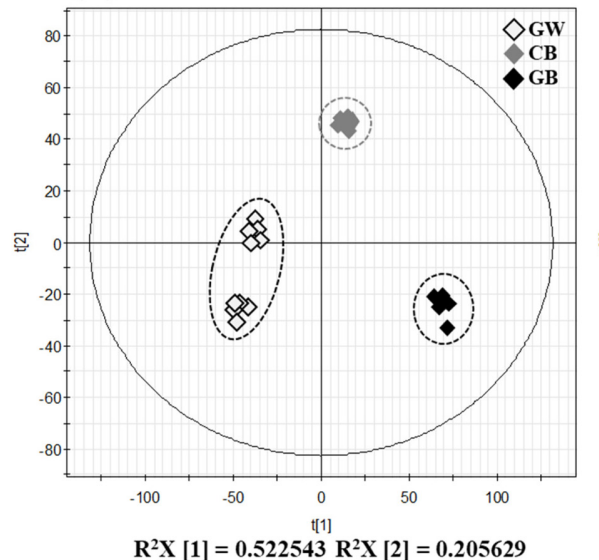

(C)

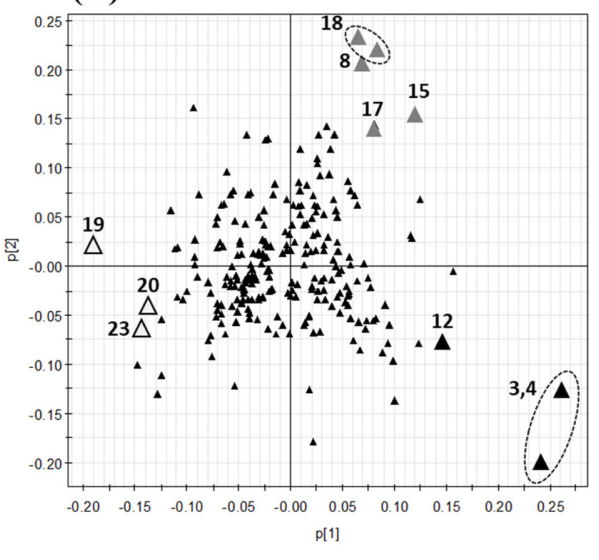

Fig. 1 Geographical locations of Artemisia gmelinii collected in South Korea (A). Principle component analysis (PCA) score plot (B) and the loading plot (C) of Artemisia gmelinii samples from different regions. GW, CB, and GB represent the provinces of Gangwon, Chungbuk, and Gyeongbuk, respectively

\section{Results and Discussion}

\section{Multivariate analysis of Artemisia gmelinii}

The simultaneous analysis of $A$. gmelinii secondary metabolites provides interrelating information that describes comprehensive variations in the metabolites of Artemisia species from different regions. To compare the metabolite levels of $A$. gmelinii between regions, we performed the principal component analysis (PCA) on the expected main peaks detected in negative ion mode (1.5-9.5 $\mathrm{min}$ ), which is a widely accepted method for profiling secondary metabolites in plant metabolomics (Fig. 1A). Based on the UPLCQTof MS-based multivariate data of $A$. gmelinii, the samples were clearly distinguished by unsupervised pattern recognition technique, such as PCA, and indicated significant differences in the levels of markers of secondary metabolites. Figure $1 \mathrm{~B}$ shows that the PCA score plot showed a clear clustering of A. gmelinii samples, indicating that the phytochemical compositions of raw materials were significantly different between the regions. Principal components 1 (PC 1, 52.3\%) and 2 (PC 2, 20.5\%) accounted for 72.8\% of the variation and showed three distinct groups. In addition, the corresponding PCA loading plot enabled the detection of several key metabolites that were responsible for group separation (Fig. 1B). Marker ions at $\mathrm{m} / \mathrm{z} 353.0854$ ([M-H] $]^{-}, 3.44 \mathrm{~min} ; 3$ and 4), 325.0969 ([M-H] $\left.]^{-}, 4.51 \mathrm{~min} ; 8\right), 463.0896$ ([M-H]-, $\left.5.08 \mathrm{~min} ; 12\right)$, $515.1227\left([\mathrm{M}-\mathrm{H}]^{-}, 5.41 \mathrm{~min} ; 15\right), 515.1143\left([\mathrm{M}-\mathrm{H}]^{-}, 5.53 \mathrm{~min}\right.$; 17), $515.1227\left([\mathrm{M}-\mathrm{H}]^{-}, 5.82 \mathrm{~min} ; \mathbf{1 8}\right), 181.0507\left([\mathrm{M}-\mathrm{H}]^{-}, 6.18\right.$ min; 19), 483.2784 ([M-H] $\left.]^{-}, 6.52 \mathrm{~min} ; 20\right), 513.1737$ ([M-H] $]^{-}$, $7.28 \mathrm{~min} ; 23$ ) were far from the center of the loading plot, which suggested that these phytochemicals were potential markers for the discrimination of $A$. gmelinii from different regions. Furthermore, variations in the content of polyphenolic compounds (e.g., 3, 4, 8, 12, 15, 17-20, and 23) as markers can be related to biological activities because these compounds have been reported to have beneficial effects such as antioxidant and anti-inflammatory properties. The relative amount of each marker in A. gmelinii considerably differed between the regions, as shown in Fig. 2. Interestingly, representative markers derived from each region appeared as the main constituents. Because the metabolite profiles of A. gmelinii from three regions were similar (Fig. 3), the quantitative difference of marker polyphenols should be influenced by environmental factors; the breeding stress of cultivated plants may result in glucose catabolism [15] and shikimate pathway [16], but it could not explain the differences of marker polyphenols because the average temperature was similar among them. Rather, the monthly precipitation and sunshine seem to be the main factors in the environment, though other factors (e.g., average temperature and relative humidity) cannot be excluded (Table 1). Specifically, polyphenols 3, 4, and $\mathbf{1 2}$ were the most abundant markers in the GB region and the lowest in the GW region, while $\mathbf{8}, \mathbf{1 5}, \mathbf{1 7}$, and 18 had the highest level in the CB region. Three polyphenols $(\mathbf{1 9}, \mathbf{2 0}$, and 23$)$ in the $\mathrm{GW}$ region were identified as important markers due to the increase in precipitation and sunshine during plant cultivation (Figs. 1-2 and Table 1). The polyphenols in higher plants were affected by pathogens, pests, feeding, weeds, wounding, temperature, wind stresses, UV light, and low manure during growth [8-10,12,13]. The produced polyphenols may be associated with plant growth, and their plant physiological role is correlated with protection against insects, microbial, and fungal infection. [17,18]. Thus, increased amounts of flavonoids can directly and/or indirectly serve as protective metabolites or precursors for the biosynthesis of other metabolites. Therefore, Artemisia species, including A. gmelinii, biosynthesize caffeoylquinic acid and produce mono, di, and tricaffeoylquinic acids. This result is important for the quality control in breeding research on A. gmelinii and Artemisia species.

\section{Tentative identification of Artemisia gmelinii}

Twenty-five compounds, including fifteen phenolic acid derivatives 

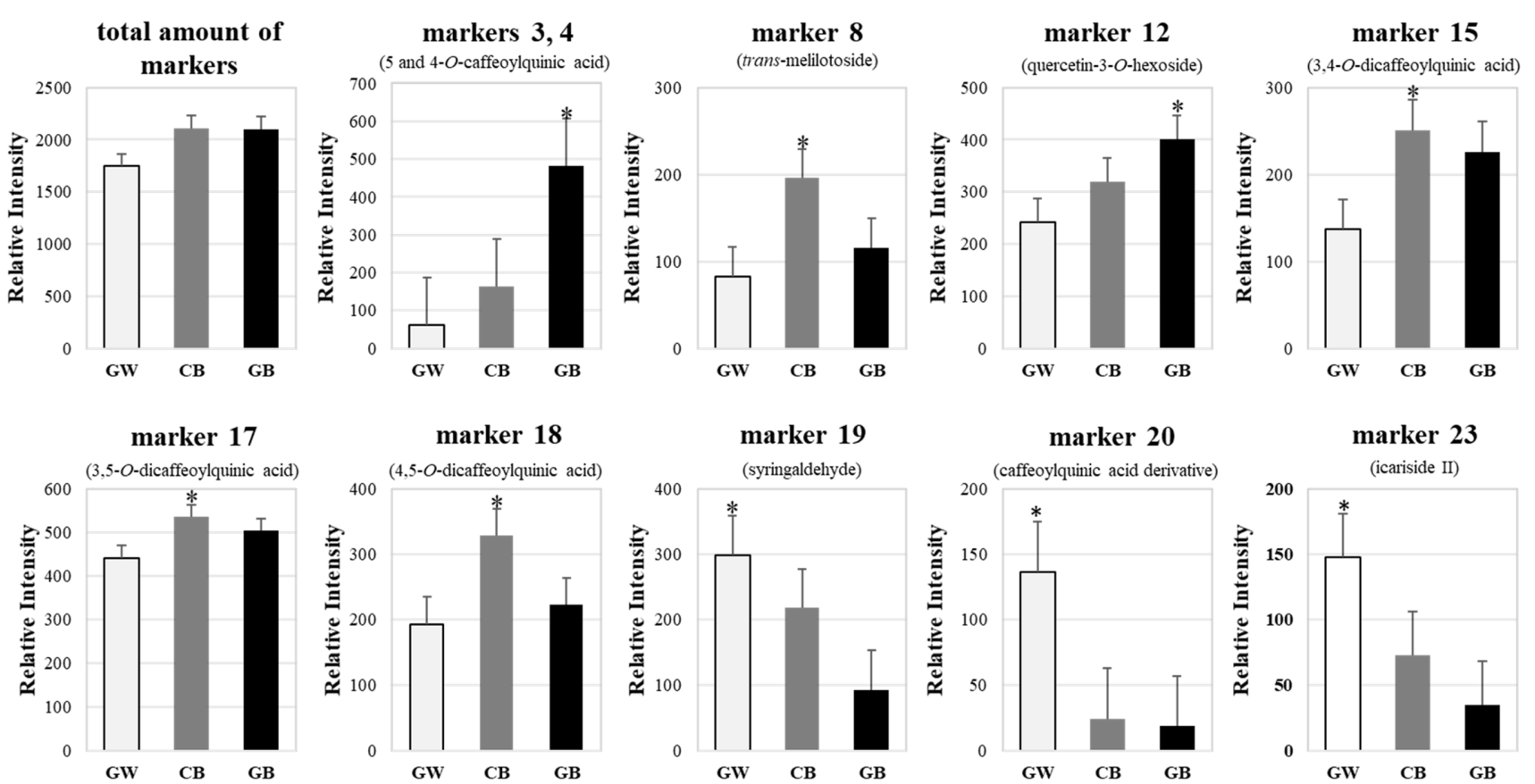

Fig. 2 Relative intensity of discriminant markers that were significantly different between geographical locations in the PCA model
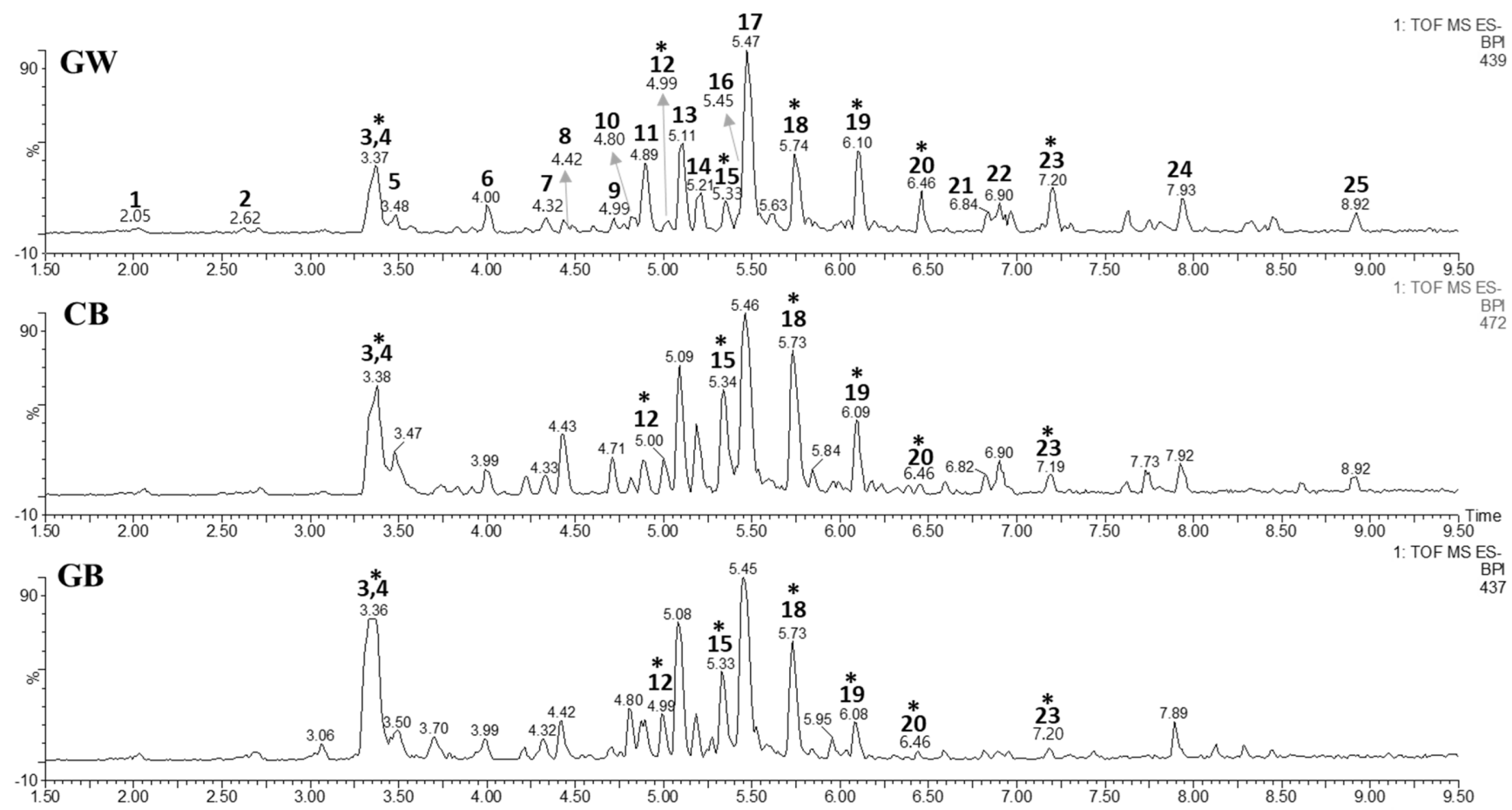

Fig. 3 Comparison of representative base peak intensity (BPI) chromatograms of Artemisia gmelinii extracts in negative mode. The star key (*) in the chromatogram represents the markers that discriminate the cultivated regions. The peaks (1-25) are listed in Table 2

$(1-5,7,8,11,15-20,22)$, six flavonols $(9,10,12-14,23)$, and four flavones $(\mathbf{6}, \mathbf{2 1}, \mathbf{2 4}, \mathbf{2 5})$ were detected in the Artemisia gmelinii extract based on the UPLC-QTof MS chromatograms (Fig. 3). Although some metabolite overlapping occurred, the base peak intensity (BPI) chromatographic separation of the metabolites was achieved within $10 \mathrm{~min}$. This approach allowed to identify many metabolites using a medium-pressure liquid partition prior to the UPLC-QTof MS analysis to reduce the matrix noise [19]. Twentythree metabolites were tentatively identified by the HRMS analysis. The MS spectra of all metabolites were carefully compared with 
those in the previously published studies on Artemisia genus (Asteraceae), including the experimental retention time, UV, $\mathrm{m} / \mathrm{z}$ values, HRESIMS data, error ppm, $\mathrm{MS}^{2}$, and molecular formulae data (Table 2) [1,20-25]. In A. gmelinii, these metabolites are structurally diverse and contain sesquiterpenes, flavone glycoside, coumarin, and phenolic acid derivatives [7,26]. The tentative identification of each metabolite focuses on the main compounds depending on the region (Fig. 3). According to the molecular ion chromatogram of the extract, the main compounds (1-18 and 2125) were tentatively identified as protocatechuic acid- $O$-glucoside (1) [1], 3-O-caffeoylquinic acid (2) [20], 5-O-caffeoylquinic acid
(3) [20], 4-O-caffeoylquinic acid (4) [20], cis-melilotoside (5) [1], apigenin 6-C-glucoside 4"-O-glucoside (6) [1], feruloylquinic acid (7) [20], trans-melilotoside (8) [1], quercetin-pentoside-hexoside (9) [20], quercetin 3-O-rhamnoside-glucoside (10) [1], 1,3-Odicaffeoylquinic acid (11) [1,20], quercetin 3- $O$-hexoside (12) [1], 6-hydroxy-7-methoxyquercetin 3-O- $\beta$ - $D$-glucopyranoside (13) [14], taxifolin 3-O-xylopyranoside (14) [15], 3,4-O-dicaffeoylquinic acid (15) [1,20], 1,5-O-dicaffeoylquinic acid (16) [1,20], 3,5-Odicaffeoylquinic acid (17) [1,20], 4,5-O-dicaffeoylquinic acid (18) $[1,20]$, syringaldehyde (19) [23], caffeoylquinic acid derivative (20) [1], luteolin (21) [20], 3,4,5-O-tricaffeoylquinic acid (22)

Table 2 Peak assignments for analysis of secondary metabolites (1-25) by UPLC-QTof MS in Artemisia gmelinii

\begin{tabular}{|c|c|c|c|c|c|c|c|c|c|}
\hline Peak & $\begin{array}{l}\text { MS RT } \\
(\min )\end{array}$ & $\begin{array}{l}\text { UV } \\
(\mathrm{nm})\end{array}$ & $\begin{array}{l}\text { Detected ion } \\
{[\mathrm{MH}]^{-}}\end{array}$ & $\begin{array}{l}\text { Calculated ion } \\
\qquad[\mathrm{MH}]^{-}\end{array}$ & $\begin{array}{l}\text { Error } \\
(\mathrm{ppm})\end{array}$ & MS/MS ions & Tentative identification & $\begin{array}{l}\text { Molecular } \\
\text { formula }\end{array}$ & References \\
\hline 1 & 2.12 & 209 & 315.0718 & 315.0716 & 0.6 & 191,151 & protocatechuic acid- $O$-glucoside & $\mathrm{C}_{13} \mathrm{H}_{16} \mathrm{O}_{9}$ & Olennikov et al. \\
\hline 2 & 2.69 & 211 & 353.0854 & 353.0873 & -5.4 & $191,175,135$ & 3-O-caffeoylquinic acid $^{\mathrm{a}}$ & $\mathrm{C}_{13} \mathrm{H}_{18} \mathrm{O}_{9}$ & Gouveia et al. \\
\hline $3^{*}$ & 3.44 & 290,325 & 353.0854 & 353.0873 & -5.4 & 191 & 5-O-caffeoylquinic acid ${ }^{\mathrm{a}}$ & $\mathrm{C}_{13} \mathrm{H}_{18} \mathrm{O}_{9}$ & Gouveia et al. \\
\hline $4^{*}$ & 3.44 & 290,325 & 353.0854 & 353.0873 & -5.4 & 191 & 4-O-caffeoylquinic acid ${ }^{\mathrm{a}}$ & $\mathrm{C}_{13} \mathrm{H}_{18} \mathrm{O}_{9}$ & Gouveia et al. \\
\hline 5 & 3.54 & $222,288,338$ & 325.0903 & 325.0923 & -6.2 & $\begin{array}{c}191,175,163 \\
119\end{array}$ & cis-melilotoside & $\mathrm{C}_{15} \mathrm{H}_{18} \mathrm{O}_{8}$ & Olennikov et al. \\
\hline 6 & 4.07 & 219,319 & 593.1520 & 593.1506 & 2.4 & $437,387,337$ & $\begin{array}{c}\text { apigenin } 6-C \text {-glucoside } 4 "-O \text { - } \\
\text { glucoside }\end{array}$ & $\mathrm{C}_{27} \mathrm{H}_{30} \mathrm{O}_{15}$ & Olennikov et al. \\
\hline 7 & 4.41 & 293,326 & 367.0994 & 367.1029 & -9.5 & 191,173 & feruloylquinic acid & $\mathrm{C}_{17} \mathrm{H}_{20} \mathrm{O}_{9}$ & Gouveia et al. \\
\hline $\mathbf{8}^{*}$ & 4.51 & $219,277,328$ & 325.0969 & 325.0923 & 14.1 & $191,163,119$ & trans-melilotoside & $\mathrm{C}_{15} \mathrm{H}_{18} \mathrm{O}_{8}$ & Olennikov et al. \\
\hline 9 & 4.79 & 265,350 & 595.1302 & 595.1299 & 0.5 & 463,300 & quercetin-pentoside-hexoside & $\mathrm{C}_{26} \mathrm{H}_{28} \mathrm{O}_{16}$ & Gouveia et al. \\
\hline 10 & 4.89 & 265,338 & 609.1429 & 609.1456 & -4.4 & 300 & $\begin{array}{c}\text { quercetin 3- } O \text {-rhamnoside- } \\
\text { glucoside }\end{array}$ & $\mathrm{C}_{27} \mathrm{H}_{30} \mathrm{O}_{16}$ & Olennikov et al. \\
\hline 11 & 4.98 & $251,290,328$ & 515.1227 & 515.1190 & 7.2 & $353,191,175$ & 1,3-O-dicaffeoylquinic acid ${ }^{\mathrm{a}}$ & $\mathrm{C}_{25} \mathrm{H}_{24} \mathrm{O}_{12}$ & $\begin{array}{l}\text { Gouveia et al., } \\
\text { Olennikov et. al. }\end{array}$ \\
\hline $12 *$ & 5.08 & 275 & 463.0896 & 463.0877 & 4.1 & 300,181 & quercetin 3-O-hexoside & $\mathrm{C}_{21} \mathrm{H}_{20} \mathrm{O}_{11}$ & Olennikov et. al. \\
\hline 13 & 5.16 & 265,348 & 493.1002 & 493.0982 & 4.1 & $330,314,287$ & $\begin{array}{c}\text { 6-hydroxy-7-methoxyquercetin } \\
\text { 3- } O-\beta \text { - } \\
\text { D-glucopyranoside }\end{array}$ & $\mathrm{C}_{22} \mathrm{H}_{21} \mathrm{O}_{13}$ & Amorim et al. \\
\hline 14 & 5.28 & 284 & 435.0901 & 435.0927 & -6.0 & & taxifolin 3-O-xylopyranoside & $\mathrm{C}_{20} \mathrm{H}_{20} \mathrm{O}_{11}$ & Mämmelä et al. \\
\hline $15^{*}$ & 5.41 & 290,326 & 515.1227 & 515.1190 & 7.2 & $\begin{array}{l}353,191,179 \\
173,161\end{array}$ & 3,4-O-dicaffeoylquinic acid ${ }^{\mathrm{a}}$ & $\mathrm{C}_{25} \mathrm{H}_{24} \mathrm{O}_{12}$ & $\begin{array}{l}\text { Gouveia et al., } \\
\text { Olennikov et al. }\end{array}$ \\
\hline 16 & 5.50 & 290.328 & 515.1227 & 515.1190 & 7.2 & $\begin{array}{l}353,191,179 \\
173,135\end{array}$ & $1,5-O$-dicaffeoylquinic acid ${ }^{\mathrm{a}}$ & $\mathrm{C}_{25} \mathrm{H}_{24} \mathrm{O}_{12}$ & $\begin{array}{l}\text { Gouveia et al., } \\
\text { Olennikov et al. }\end{array}$ \\
\hline $17^{*}$ & 5.53 & $251,290,328$ & 515.1143 & 515.1190 & -9.1 & 353,191 & 3,5-O-dicaffeoylquinic acid ${ }^{\mathrm{a}}$ & $\mathrm{C}_{25} \mathrm{H}_{24} \mathrm{O}_{12}$ & $\begin{array}{l}\text { Gouveia et al., } \\
\text { Olennikov et al. }\end{array}$ \\
\hline $18 *$ & 5.82 & $251,290,328$ & 515.1227 & 515.1190 & 7.2 & $\begin{array}{l}353,191,179 \\
173,135\end{array}$ & 4,5-O-dicaffeoylquinic acid ${ }^{\mathrm{a}}$ & $\mathrm{C}_{25} \mathrm{H}_{24} \mathrm{O}_{12}$ & $\begin{array}{l}\text { Gouveia et al., } \\
\text { Olennikov et al. }\end{array}$ \\
\hline $19 *$ & 6.18 & 284 & 181.0507 & 181.0501 & 33 & 166,146 & syringaldehyde & $\mathrm{C}_{9} \mathrm{H}_{10} \mathrm{O}_{4}$ & Sanz et al. \\
\hline $20 *$ & 6.52 & 326 & 483.2784 & 483.2805 & -4.3 & 353,191 & caffeoylquinic acid derivative & $\mathrm{C}_{25} \mathrm{H}_{23} \mathrm{O}_{10}$ & Martucci et al. \\
\hline 21 & 6.91 & 285 & 285.0349 & 285.0399 & -17.5 & - & luteolin & $\mathrm{C}_{25} \mathrm{H}_{10} \mathrm{O}_{6}$ & Gouveia et al. \\
\hline 22 & 6.98 & 290,327 & 677.1522 & 677.1506 & 2.4 & $\begin{array}{c}525,515,353 \\
191\end{array}$ & 3,4,5-O-tricaffeoylquinic acid ${ }^{\mathrm{a}}$ & $\mathrm{C}_{34} \mathrm{H}_{30} \mathrm{O}_{15}$ & Gouveia et al. \\
\hline $23 *$ & 7.28 & 289 & 513.1737 & 513.1761 & -4.7 & $367,181,166$ & icariside II & $\mathrm{C}_{27} \mathrm{H}_{30} \mathrm{O}_{10}$ & Jianpeng et al. \\
\hline 24 & 8.00 & 275 & 329.0666 & 329.0661 & 1.5 & 314 & $\begin{array}{l}\text { 5,7,3'-trihydroxy-6,4'- } \\
\text { dimetoxyflavone }\end{array}$ & $\mathrm{C}_{17} \mathrm{H}_{14} \mathrm{O}_{7}$ & Olennikov et al. \\
\hline 25 & 8.97 & 265 & 299.0546 & 299.0556 & -3.3 & - & 3'-hydroxygenkwanin & $\mathrm{C}_{16} \mathrm{H}_{12} \mathrm{O}_{6}$ & Olennikov et al. \\
\hline
\end{tabular}

The star key $\left(^{*}\right)$ on peak no. represents the key markers that discriminate the cultivation regions

${ }^{\text {a } I d e n t i f i e d ~ b y ~ c o m p a r i n g ~ e x p e r i m e n t a l ~ d a t a ~ w i t h ~ t h o s e ~ o f ~ s t a n d a r d ~ c o m p o u n d s ~}$ 
[20], icariside II (23) [24], 5,7,3'-trihydroxy-6,4'-dimetoxyflavone (24) [1], 3'-hydroxygenkwanin (25) [1] by comparing with the data from the previous studies on Artemisia genus. Compounds 3, $4,15,17$, and 18 were determined to be mono- and di-caffeoylquinic acids. The MS/MS analysis of monocaffeoylquinic acid (3 and 4) and dicaffeoylquinic $(\mathbf{1 5}, \mathbf{1 7}$, and 18) acid produced a common fragment at $m / z$ 191, which corresponds to quinic acid (Table 2). The intensity of quinic acid peaks in a sample can be a structural marker for mono- and di-caffeoylquinic acids. In addition, a typical fragmentation pattern of dicaffeoylquinic acid was founded at $m / z 353$ [caffeoylquinic acid-H] $]^{-}, m / z 191$ [quinic acid-H] ${ }^{-}, \mathrm{m} / z$ 179 [caffeoyl acid-H] ${ }^{-}, m / z 173$ [quinic acid- $\left.\mathrm{H}_{2} \mathrm{O}-\mathrm{H}\right]^{-}$and $m / z 135$ [caffeoyl acid- $\left.\mathrm{CO}_{2}-\mathrm{H}\right]^{-}[25]$. Because the characteristic fragments of compounds 8 and 20 were found at $\mathrm{m} / z 191$ [quinic acid-H]', $m / z 163$ [hydroxycinnamic acid-H] ${ }^{-}, m / z 119$ [hydroxycinnamic

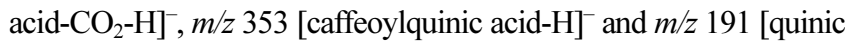
acid-H]', compounds $\mathbf{8}$ and $\mathbf{2 0}$ were tentatively identified as melilotoside and caffeoylquinic acid derivatives, respectively [1, 25]. Compounds $\mathbf{1 2}$ and $\mathbf{2 3}$ were determined to be flavonol hexosides. Due to an even more pronounced radical loss of the hexoside with a homolytic bond cleavage of the $O$-hexoside bond, the MS/MS spectra of flavonol hexosides exhibited a common fragmentation parent ion [M-hexoside- $\mathrm{H}]^{-}$that corresponds to flavonols (Table 2) [27]. In MS/MS spectra of compounds 12 and 23, which were determined to be quercetin 3-O-hexoside and icaritin 3-O-hexoside (icariside II), respectively, the typical fragmentation patterns were found at $\mathrm{m} / \mathrm{z} 301$ [quercetin-H] ${ }^{-}, \mathrm{m} / \mathrm{z}$ 300 [quercetin-2H] $^{-}$and at $m / z 367$ [icaritin-H] .

The metabolites of $A$. gmelinii were analyzed to discriminate the origin and quality control by multivariate analysis using UPLCQTof MS. In summary, polyphenols changes in A. gmelinii samples demonstrated that geographical cultivation may be discriminated by polyphenols, and ten markers $(3,4,8,12,15,17$ 20, 23) were important for three regions of Korea. The contents of individual markers were significantly different, while the total amounts of markers were very similar between the groups. The changes in polyphenols provided insights into the secondary metabolism in plants depending on geographical conditions. These chemometric markers of $A$. gmelinii have the potential to be useful for identifying botanical raw material, regard of the strategy employed to carry out authenticity, as these strategies are in continuous development. Therefore, data on the composition analysis of polyphenols in $A$. gmelinii could shown important information to consumers, researchers, and producers in the related industry.

Acknowledgments This work was conducted with the support of the Cooperative Research Program for Agriculture Science and Technology Development (Project No. PJ01420404) of the Rural Development Administration, Republic of Korea

\section{References}

1. Olennikov DN, Nadezhda K, Chirikova NK, Kashchenko NI, Nikolaev VM, Kim SW, Vennos C (2018) Bioactive phenolics of the aenus Artemisia (Asteraceae): HPLC-DAD-ESI-TQ-MS/MS profile of the siberian species and their inhibitory potential against $\alpha$-amylase and $\alpha$ glucosidase. Front Pharmacol 9: 756

2. Govorko D, Logendra S, Wang Y, Esposito D, Komarnytsky S, Ribnicky D, Poulev A, Wang Z, Cefalu WT, Ilya Raskin I (2017) Polyphenolic compounds from Artemisia dracunculus L. inhibit PEPCK gene expression and gluconeogenesis in an H4IIE hepatoma cell line. Am J Physiol Endocrinol Metab 293: 1503-1510

3. Yamamoto N, Kanemoto Y, Ueda M, Kawasaki K, Fukuda I, Ashida H (2011) Anti-obesity and anti-diabetic effects of ethanol extract of Artemisia princeps in C57BL/6 mice fed a high-fat diet. Food Funct 2: 45

4. Karabegović I, Nikolova M, Veličković D, Saša Stojičević S, Vlada Veljković V, Lazić M (2011) Comparison of antioxidant and antimicrobial activities of methanolic extracts of the Artemisia sp. recovered by different extraction techniques. Chin J Chem Eng 19(3): 504-511

5. Seo JM, Kang HM, Son KH, Kim JH, Lee CW, Kim HM, Chang SI, Kwon BM (2003) Antitumor activity of flavones isolated from Artemisia argyi. Planta Med 69(3): 218-222

6. Liu KCSC, Yang SL, Roberts MF, Elford BC, Phillipson JD (1992) Antimalarial activity of Artemisia апnиa flavonoids from whole plants and cell cultures. Plant Cell Reports 11: 637-640

7. Árpád K, Zoltán B, Márta MS, Attila R, Viktor H, Judit H, Imre M, Csaba S, György MK, György TB (2012) Antioxidant activity-guided phytochemical investigation of Artemisia gmelinii Webb. ex Stechm.: Isolation and spectroscopic challenges of 3,5-O-dicaffeoyl (epi?) quinic acid and its ethyl ester. J Pharm Biomed Anal 59: 83-89

8. Yuk HJ, Ryu HW, Kim DY, Park MH, Seo WD, Jeong SH, Oh SR (2019) Comparison of flavonoid and policosanol profiles in Korean winter-spinach (Spinacia oleracea L.) cultivated in different regions. Food Chem 279: 202-208

9. Yuk HJ, Oh KY, Kim DY, Song HH, Kim JY, Oh SR, Ryu HW (2017) Metabolomic Profiling, Antioxidant and Anti-inflammatory Activities of Hypericum Species Growing in South Korea. Nat Prod Commun 12(7): 1041-1044

10. An JH, Yuk HJ, Kim DY, Nho CW, Lee DH, Ryu HW, Oh SR (2018) Evaluation of phytochemicals in Agastache rugosa (Fisch. \& C.A.Mey.) Kuntze at different growth stages by UPLC-QTof-MS. Ind Crops Prod 112: 608-616

11. Park MH, Lee SM, Ko SK, Oh KY, Kim JH, Kim H, Kwon MC, Ryoo IJ, Ahn JS, Ryu HW, Oh SR (2018) Analysis of active metabolites of Sophora flavescens for indoleamine 2,3-dioxygenase and monoamine oxidases using ultra-performance liquid chromatography-quadrupole time-of-flight mass spectrometry. Nat Prod commun 13(12): 1649-1653

12. Song HH, Kim DY, Woo, SY, Lee HK, Oh SR (2013) An approach for simultaneous determination for geographical origins of Korean Panax ginseng by UPLC-QTOF/MS coupled with OPLS-DA models. J Ginseng Res 37(3): 341-348

13. Ryu HW, Song HH, Kim KO, Park YJ, Kim DY, Kim JH, Oh SR (2016) Secondary metabolite profiling and modulation of antioxidants in wild and cultivated Euphorbia supine. Ind Crops Prod 89: 215-224

14. Lee JH, Park MJ, Ryu HW, Yuk HJ, Choi SW, Lee KS, Kim SL, Seo WD (2016) Elucidation of phenolic antioxidants in barley seedlings (Hordeum vulgare L.) by UPLC-PDA-ESI/MS and screening for their contents at different harvest times. J Funct Foods 26: 667-680

15. Maciejewska U, Bogatek R (2002) Glucose catabolism in leaves of cold- 
treated winter rape plants. J Plant Physiol 159(4): 397-402

16. Schulz E, Tohge T, Zuther E, Fernie AR, Hincha DK (2016) Flavonoids are determinants of freezing tolerance and cold acclimation in Arabidopsis thaliana. Scientific Reports 6: 34027

17. Barbehenn RV, Constabel CP (2011) Tannins in plant-herbivore interactions. Phytochem 72(13): 1551-1565

18. Khanbabaee K, van Ree T (2001) Tannins: classification and definition. Nat Prod Rep 18: 641-649

19. Scoparo CT, Souza LM, Dartora N, Sassaki GL, Gorin PA, Iacomini M (2012) Analysis of Camellia sinensis green and black teas via ultra high performance liquid chromatography assisted by liquid-liquid partition and two-dimensional liquid chromatography (size exclusion $\times$ reversed phase). J Chromatogr A 1222: 29-37

20. Gouveia SC, Castilho PC (2013) Artemisia annua L.: Essential oil and acetone extract composition and antioxidant capacity. Ind Crops Prod 45: $170-181$

21. Amorim MR, Rinaldo D, Amaral FP, Vilegas W, Magentad MAG, Vieira GM, Santos LD (2014) HPLC-DAD based method for the quantification of flavonoids in the hydroethanolic extract of Tonina fluviatilis Aubl. (Eriocaulaceae) and their radical scavenging activity. Quim Nova 37(7): $1122-1127$

22. Mämmelä $P$ (2001) Phenolics in selected european hardwood species by liquid chromatography-electrospray ionisation mass spectrometry. Analyst
126: $1535-1538$

23. Sanz M, Simón BF, Cadahí E, Esteruelas E, Muñoz AM, Teresa Hernández T, Estrella I, Pinto E (2012) LC-DAD/ESI-MS/MS study of phenolic compounds in ash (Fraxinus excelsior L. and F. americana L.) heartwood. Effect of toasting intensity at cooperage. J Mass Spectrom 47: 905-918

24. Jianpeng DOU, Zhiqiang LIU, Shuying LIU (2006) Structure identification of a prenylflavonol glycoside from Epimedium koreanum by electrospray ionization tandem mass spectrometry. Anal Sci 22: 449-452

25. Meng Xue M, Hang Shi H, Jiao Zhang J, Qing-Quan Liu QQ, Jun Guan J, Zhang JY, Qun Ma Q (2016) Stability and degradation of caffeoylquinic acids under different storage conditions studied by highperformance liquid chromatography with photo diode array detection and high-performance liquid chromatography with electrospray ionization collision-induced dissociation tandem mass spectrometry. Molecules 21: 948

26. Zeng WZ, Quesheng, Zhang QY, Liang H (2014) Two new oplopane sesquiterpenes from Artemisia gmelinii Web. ex Stechm. Chin Chem Lett 25: 1153-1156

27. Hvattum E, Ekeberg D (2003) Study of the collision-induced radical cleavage of flavonoid glycosides using negative electrospray ionization tandem quadrupole mass spectrometry. J Mass Spectrom 38: 43-49 